\title{
Crystal structure and Hirshfeld analysis of the kryptoracemate: bis(mefloquinium) chloride p-fluorobenzenesulphonate
}

\author{
Mukesh M. Jotani $^{* I}$, James L. Wardell ${ }^{* I I}$, and Edward R. T. Tiekink ${ }^{* I I I}$ \\ ${ }^{\text {I }}$ Bhavan's Sheth R. A. College of Science, Department of Physics, Ahmedabad, Gujarat 380001, India \\ II Centro de Desenvolvimento Tecnológico em Saúde (CDTS), Fundação Oswaldo Cruz (FIOCRUZ), Casa Amarela, Campus de \\ Manguinhos, Av. Brasil 4365, 21040-900 Rio de Janeiro, RJ, Brazil \\ III Sunway University, Centre for Crystalline Materials, Faculty of Science and Technology, 47500 Bandar Sunway, Selangor Darul Ehsan, \\ Malaysia
}

Received; accepted

Keywords: Mefloquine / kryptoracemate / Hirshfeld surface / crystal structure analysis / X-ray diffraction

\begin{abstract}
The crystal structure analysis of bis(mefloquinium) chloride $\mathrm{p}$-fluorobenzenesulphonate salt reveals a rare example of a kryptoracemate given that the cations exhibit a non-crystallographic enantiomeric relationship. The conformations of the cations are based on a skewed letter $\mathrm{L}$ with the (piperidinium-2-yl)methanol group sitting almost normal to and directed away from the quinolinyl residue. The most prominent feature of the molecular packing is the formation of supramolecular helical chains along the $a$-axis, being sustained by pairs of hydroxyl-O- $-\mathrm{H} \cdots \mathrm{O}$ (sulphonate), piperidinium- $\mathrm{N}-\mathrm{H} \cdots \mathrm{O}$ (sulfonate) and piperidinium- $\mathrm{N}-\mathrm{H} \cdots \mathrm{Cl}$ hydrogen bonding. Geometric and Hirshfeld surface analyses of the crystal structure shows significant differences in supramolecular aggregation between the cations due to the presence of different anions and this is the likely reason for the observed kryptoracemic behaviour.
\end{abstract}

* Correspondence authors: mmjotani@ rediffmail.com (M.M.J.); j.wardell@abdn.ac.uk (J.L.W.); edwardt@ sunway.edu.my (E.R.T.T.) 


\section{Introduction}

The quinolinyl-derivative, mefloquine, Fig. 1, manufactured and used as the racemic erythro-mefloquine hydrochloride, i.e. $\left[\left(R^{*}, S^{*}\right)-(2-\{[2,8\right.$-bis(trifluoromethyl)quinolin-4-yl] (hydroxymethyl)piperidin-1-ium chloride, has been used as an anti-malarial drug since 1971 [1], branded, for example, as Lariam ${ }^{\circledR}$, Mephaquin ${ }^{\circledR}$ and Mefliam ${ }^{\circledR}$. More recently, the anti-bacterial [2, 3], anti-mycobacterial [4-6] and anti-cancer [7] potential of mefloquine and derivatives has been investigated. With these applications in mind, it is not surprising that there have been several crystal structures reported for analogues of the mefloquinium cation and of related species (vide infra). Generally, the crystallographic studies have revealed a similar conformation for the mefloquinium cations in all the characterised salts. However, the intermolecular arrangements differ appreciably depending on the nature of co-crystallised species. During the course of investigations of mefloquinium cations, the title salt, bis(mefloquinium) chloride p-fluorobenzenesulfonate. $\mathbf{1}$, was isolated and characterised crystallographically. The asymmetric unit of this salt comprises two independent cations, a chloride and a $\mathrm{p}$ fluorobenzenesulphonate anion. The curious observation is that the cations are pseudo racemic, i.e. one having $R-, S$ - configurations of the chiral centres, and the other having $S-, R$ configurations. Such behaviour in crystallography has been given the term "kryptoracemate", terminology ascribed to Ivan Bernal [8] where the Greek-derived prefix, krypto, refers to the hidden racemic nature of the compound.

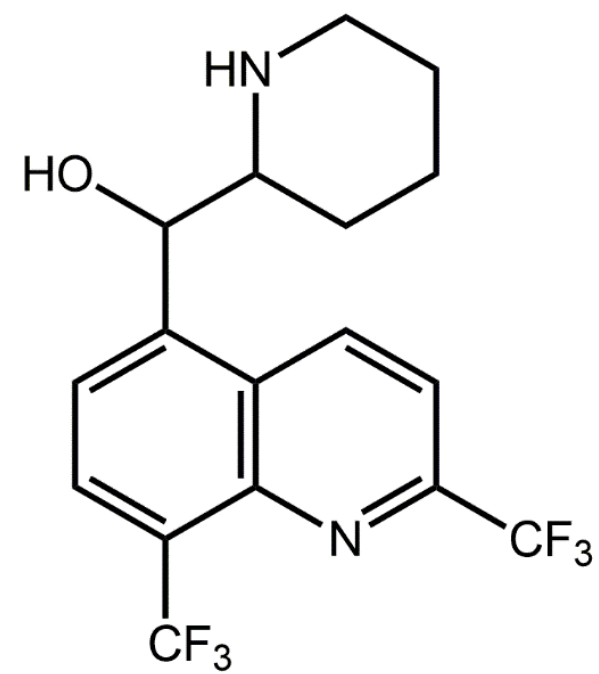

Fig. 1. Chemical structure of [2,8-bis(trifluoromethyl)quinolin-5yl](piperidin-2-yl)methanol, mefloquine.

Under normal circumstances, if species, e.g. molecules, can pack about a centre of inversion, they will $[9,10]$ so kryptoracemates are rare. Crystallographic criteria include i) the compound must crystallise in one of the 65 Sohncke space groups (i.e. devoid of inversion centres, rotatory inversion axes, glide planes or mirror planes), and ii) $Z^{\prime}$ is usually greater than 1 (unless the molecule lies on a rotation axis). The phenomenon of kryptoracemates in organic systems has been surveyed recently by Fábián and Brock [11]. In this review it was noted that kryptoracemates comprise only 0.1 
$\%$ of all structures implying that $99.9 \%$ of racemic compounds, molecules with meso symmetry and achiral molecules will crystallise about a centre of inversion. While the focus here is upon organic molecules, kryptoracemates are also found in organometallic compounds [12]. Herein, the crystallographic characterisation of a mefloquinium salt (1), an example of a kryptoracemate, is described along with an analysis of its Hirshfeld surface.

\section{Experimental}

\section{Synthesis and characterisation}

To a solution of mefloquinium chloride $(2 \mathrm{mmol})$ and $\mathrm{p}$ fluorobenzenesulphonyl chloride $(2 \mathrm{mmol})$ in acetone (20 $\mathrm{ml})$ was added sodium hydroxide $(3 \mathrm{mmol})$. The reaction mixture was gently heated for 30 minutes and set aside at room temperature. The crystals of the title compound, which slowly formed were collected, and recrystallised from EtOH. The crystals slowly decomposed on heating. IR [KBr]: 3447, $2925,1586,1450,1204 \mathrm{~cm}^{-1}$.

\section{Crystal structure determination}

Intensity data were measured at $100 \mathrm{~K}$ on a Rigaku Saturn724+ CCD with Mo K $\alpha$ radiation. Data processing and absorption correction were accomplished with CrystalClearSM Expert [13]. The structure was solved using direct methods with SHELXS-97 [14], and refined on $F^{2}$ by full-matrix least-squares with anisotropic displacement parameters for all non-hydrogen atoms using SHELXL-2014/7 [15]. The $\mathrm{C}$-bound $\mathrm{H}$ atoms were placed in their idealised positions (0.95-1.00 $\AA$ ) and refined in the riding model approximation with $U_{\text {iso }}=1.2 U_{\text {eq }}$ (carrier atom). The O- and N-bound $\mathrm{H}$ atoms were located from a Fourier map and then refined with $\mathrm{O}-\mathrm{H}=0.84 \pm 0.01$ and $\mathrm{N}-\mathrm{H}=0.88 \pm 0.01 \AA$, respectively, and with $U_{\text {iso }}=1.5 U_{\text {eq }}(\mathrm{O})$ and $U_{\text {iso }}=1.2 U_{\text {eq }}(\mathrm{N})$. A weighting scheme of the form $w=1 /\left[\sigma^{2}\left(F_{\mathrm{o}}{ }^{2}\right)+(0.045 P)^{2}+0.610 P\right]$ where $P=\left(F_{\mathrm{o}}{ }^{2}+2 F_{\mathrm{c}}{ }^{2}\right) / 3$ was introduced. Unit cell data, $\mathrm{X}$ ray data collection parameters, and details of the structure refinement are given in Table 1. The programs WinGX [16], ORTEP-3 for Windows [16], PLATON [17], QMol [18], DIAMOND [19] and Mercury [20] were also used in the analysis.

In response to the possibility of $\mathbf{1}$ having a higher symmetry space group, as indicated by the PLATON [17] alerts, in particular the presence of a (pseudo) centre of inversion with an $89 \%$ fit, centrosymmetric Pnma was evaluated, the contraventions of the systematic absences notwithstanding. In Pnma, the two mefloquinium cations are related by a pseudo centre of symmetry and the chloride anion can be readily shifted onto a mirror plane. However, the p-fluorobenzenesulphonate anion does not conform to the required mirror symmetry in the higher symmetry space group, i.e. the non-fitted atoms with no symmetry related counterpart in Pnma are the S1, F13, O4, O5, C36-40 atoms. Finally, a comment on the Flack parameter, i.e. 0.25(2), is appropriate. A careful analysis of the structure factor data employing the routines in PLATON [17] did not indicate the presence of 
twinning in the studied sample. It is likely that the large deviation from 0 and the large standard uncertainty values are due to the pseudo centrosymmetric relationship in the major proportion of the asymmetric unit.

Table 1. Crystallographic data and refinement details for $\mathbf{1} .^{l}$

\begin{tabular}{|c|c|}
\hline Formula & $\begin{array}{l}2\left(\mathrm{C}_{17} \mathrm{H}_{17} \mathrm{~F}_{6} \mathrm{~N}_{2} \mathrm{O}\right), \mathrm{Cl}, \\
\mathrm{C}_{6} \mathrm{H}_{4} \mathrm{FO}_{3} \mathrm{~S}\end{array}$ \\
\hline Formula weight & 969.25 \\
\hline Crystal colour, habit & Colourless, block \\
\hline Crystal size/mm & $0.09 \times 0.12 \times 0.12$ \\
\hline Crystal system & orthorhombic \\
\hline Space group & $P 2_{1} 2_{1} 2_{1}$ \\
\hline$a / \AA$ & $12.0782(5)$ \\
\hline$b / \AA$ & 13.9253(6) \\
\hline$c / \AA$ & $25.3280(17)$ \\
\hline$V / \AA^{3}$ & $4260.0(4)$ \\
\hline$Z / Z^{\prime}$ & $4 / 1$ \\
\hline$D_{\mathrm{c}} / \mathrm{g} \mathrm{cm}^{-3}$ & 1.511 \\
\hline$F(000)$ & 1984 \\
\hline$\mu(\mathrm{Mo} K \alpha) / \mathrm{mm}^{-1}$ & 0.245 \\
\hline Measured data & 22379 \\
\hline$\theta$ range $/^{\circ}$ & $3.0-27.5$ \\
\hline Unique data & 9675 \\
\hline$R_{\text {int }}$ & 0.024 \\
\hline Observed data $(I \geq 2.0 \sigma(I))$ & 9007 \\
\hline$R$, obs. data; all data & $0.030 ; 0.076$ \\
\hline$R_{\mathrm{w}}$, obs. data; all data & $0.034 ; 0.078$ \\
\hline Flack parameter & $0.25(2)$ \\
\hline
\end{tabular}

${ }^{1}$ Supplementary Material: Crystallographic data (excluding structure factors) for the structures reported in this paper have been deposited with the Cambridge Crystallographic Data Centre as supplementary publication no. CCDC-1436547. Copies of available material can be obtained free of charge, on application to CCDC, 12 Union Road, Cambridge CB2 1EZ, UK, (fax: +44-(0)1223336033 or e-mail: deposit@ ccdc.cam.ac.uk). The list of Fo/Fc-data is available from the author up to one year after the publication has appeared.

\section{Results and discussion}

\section{Crystal and molecular structures}

The crystallographic asymmetric unit of 1, Fig. 1, comprises two independent mefloquinium cations, a chloride and a pfluorobenzenesulphonate anion. The crystallographic characterisation shows that only partial substitution of chloride in mefloquinium chloride by p-fluorobenzenesulphonate had occurred during the crystallisation reaction. The mefloquinium cations are related by a pseudo centre of inversion with the N1-containing molecule having $S$ - and $R$-configurations at the $\mathrm{C} 12$ and $\mathrm{C} 13$ chiral centres, respectively, and the N3- 
containing molecule having $R$ - and $S$-configurations, respectively, for the C29 and C30 atoms. Hence, the crystal is an example of a kryptoracemate. Each cation comprises a quinolinyl fused ring system connected to a (piperidinium-2yl)methanol group. Confirmation that the original piperidin2-yl group has been protonated was found by the observation of residual electron density peaks about each nitrogen atom and in the pattern of intermolecular interactions (see below). Each cation features an intramolecular piperidinium-N$\mathrm{H} \cdots \mathrm{O}$ (hydroxyl) hydrogen bond, Table 2. The dihedral angles between the quinolinyl residue and the least-squares plane through the piperidinium-2-yl ring, each with a chair conformation, are 59.67(5) and 64.63(5) ${ }^{\circ}$ for the N1- and N3containing molecules, respectively. Overall, the cations each adopt the shape of a skewed $\mathrm{L}$. The cations are quite similar and the best fit between the inverted form for the N1-containing molecule with the N2-containing molecule shown in Fig. 3. The r.m.s. bond length and angle fits are $0.0049 \AA$ and $0.484^{\circ}$, respectively [17]. See below for discussion on the conformations of the cation and literature precedents.

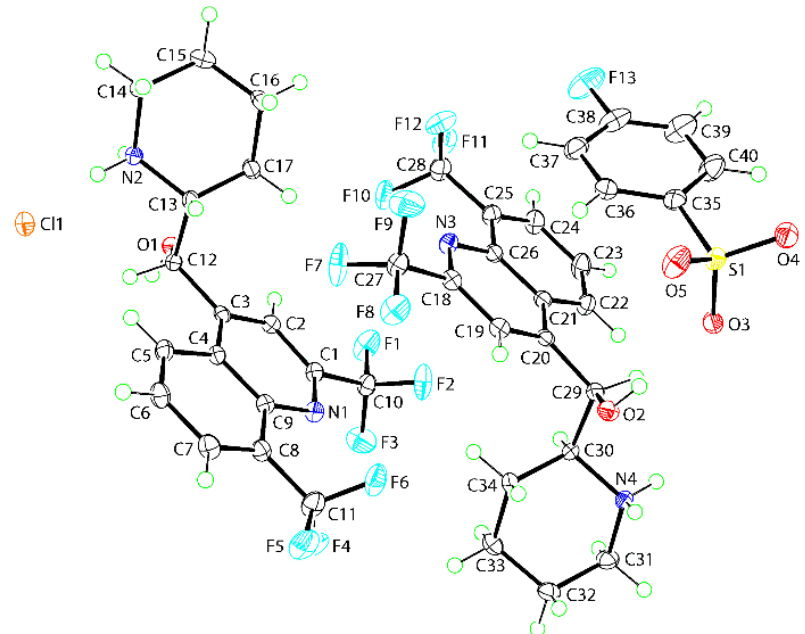

Fig. 2. Molecular structure of the four ions comprising 1 showing the atom labelling scheme. The diagram is drawn at the $50 \%$ probability level.

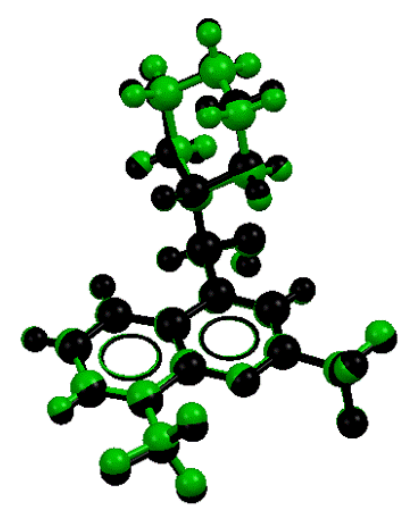

Fig. 3. Overlay diagram of the mefloquinium cations in 1: N1-containing cation (black image) and inverted N3-containing cation (green).

The deviations from mirror symmetry of the p-fluorobenzenesulphonate anion, a requirement if the higher symmetry 
space group was correct (see Crystal structure determination), are manifested in the variations in the torsion angles involving the sulfonate- $\mathrm{O}$ atoms, indicating a twist in the molecule that cannot be accommodated on a mirror plane. Thus, the O3-S1-C35-C36 and O3-S1-C35-C40 torsion angles of $90.95(17)$ and $-86.07(18)^{\circ}$, respectively, deviate from the ideal $90^{\circ}$. Further twists are observed in the pairs O4-S1-C35-C36 [-150.83(16) $\left.)^{\circ}\right]$ and O5-S1-C35-C40 [153.76 (17) $\left.{ }^{\circ}\right]$, and O4-S1-C35-C40 [32.15(19) $\left.)^{\circ}\right]$ and O5S1-C35-C36 [-29.22(19) $\left.{ }^{\circ}\right]$ torsion angles. 
Table 2. Summary of intermolecular interactions $\left(\mathrm{A}-\mathrm{H} \cdots \mathrm{B} ; \stackrel{\AA}{\mathrm{A}},^{\circ}\right)$ operating in the crystal structure of $\mathbf{1} .^{l}$

\begin{tabular}{|c|c|c|c|c|c|c|c|}
\hline A & $\mathrm{H}$ & $\mathrm{B}$ & A-H & $\mathrm{H} \cdots \mathrm{B}$ & $A \cdots B$ & $\mathrm{~A}-\mathrm{H} \cdots \mathrm{B}$ & $\begin{array}{l}\text { Symmetry opera- } \\
\text { tion }\end{array}$ \\
\hline $\mathrm{N} 2$ & $\mathrm{H} 2 \mathrm{n}$ & $\mathrm{O} 1$ & $0.916(15)$ & $2.42(2)$ & $2.802(2)$ & $104.8(17)$ & $x, y, z$ \\
\hline $\mathrm{N} 4$ & $\mathrm{H} 3 \mathrm{n}$ & $\mathrm{O} 2$ & $0.923(14)$ & $2.46(2)$ & $2.815(2)$ & $102.8(17)$ & $x, y, z$ \\
\hline $\mathrm{O} 1$ & H1o & O3 & $0.84(2)$ & $1.94(2)$ & $2.759(2)$ & $163(3)$ & $11 / 2-x, 1-y, 1 / 2+z$ \\
\hline $\mathrm{N} 2$ & H1n & $\mathrm{Cl1}$ & $0.93(2)$ & $2.16(2)$ & $3.0654(19)$ & $167.4(18)$ & $x, y, z$ \\
\hline $\mathrm{N} 2$ & $\mathrm{H} 2 \mathrm{n}$ & $\mathrm{O} 5$ & $0.916(15)$ & $1.98(2)$ & $2.730(2)$ & $138(2)$ & $1-x,-1 / 2+y, 1 / 2-z$ \\
\hline $\mathrm{O} 2$ & $\mathrm{H} 2 \mathrm{o}$ & $\mathrm{O} 3$ & $0.84(2)$ & $1.93(2)$ & $2.744(2)$ & $164(3)$ & $x, y, z$ \\
\hline $\mathrm{N} 4$ & $\mathrm{H} 3 \mathrm{n}$ & $\mathrm{O} 4$ & $0.923(14)$ & $1.916(17)$ & $2.782(2)$ & $156(2)$ & $1 / 2+x, 11 / 2-y,-z$ \\
\hline $\mathrm{N} 4$ & $\mathrm{H} 4 \mathrm{n}$ & $\mathrm{Cl} 1$ & $0.927(19)$ & $2.20(2)$ & $3.0982(19)$ & 164.1(19) & $1 \frac{1}{2}-x, 1-y,-1 / 2+z$ \\
\hline $\mathrm{C} 40$ & $\mathrm{H} 40$ & $\mathrm{Cg}(\mathrm{N} 1, \mathrm{C} 1-\mathrm{C} 4, \mathrm{C} 9)$ & 0.95 & 2.64 & $3.473(3)$ & 147 & $1 \frac{1}{2}-x, 1-y,-1 / 2+z$ \\
\hline $\mathrm{C} 10$ & F3 & $\mathrm{Cg}(\mathrm{N} 3, \mathrm{C} 18-\mathrm{C} 21, \mathrm{C} 26)$ & $1.328(3)$ & $3.0742(18)$ & $4.148(2)$ & $137.18(15)$ & $x, y, z$ \\
\hline $\mathrm{C} 11$ & F5 & $\mathrm{Cg}(\mathrm{C} 21-\mathrm{C} 26)$ & $1.345(3)$ & $3.7858(19)$ & $4.787(3)$ & $131.66(14)$ & $2-x, 1 / 2+y, 1 / 2-z$ \\
\hline $\mathrm{C} 27$ & F7 & $\mathrm{Cg}(\mathrm{N} 1, \mathrm{C} 1-\mathrm{C} 4, \mathrm{C} 9)$ & $1.332(3)$ & $3.0976(19)$ & $4.126(2)$ & $133.28(16)$ & $x, y, z$ \\
\hline $\mathrm{C} 28$ & F11 & $\mathrm{Cg}(\mathrm{C} 4-\mathrm{C} 9)$ & $1.343(3)$ & $3.4841(19)$ & $4.479(3)$ & $130.80(14)$ & $1-x,-1 / 2+y, 1 / 2-z$ \\
\hline
\end{tabular}

${ }^{1} \mathrm{Cg}$ corresponds to the ring centroid of the specified atoms. 
The key feature of the molecular packing is the formation of helical ( $2_{1}$ symmetry) supramolecular chains along the $a$ axis. These are sustained by hydroxyl-O- $\mathrm{H} \cdots \mathrm{O}$ (sulphonate), piperidinium- $\mathrm{N}-\mathrm{H} \cdots \mathrm{O}$ (sulfonate) and piperidinium- $\mathrm{N}-\mathrm{H} \cdots \mathrm{Cl}$ hydrogen bonding, Fig. 4a and Table 2. The "symmetry" in the hydrogen bonding is evident from Fig. 4a where the sulfonate-O3 atom is bifurcated and each of the sulfonate-O4 and $\mathrm{O} 5$ atoms accepts a hydrogen bond from a piperidinium$\mathrm{N}-\mathrm{H}$ atom. It is noted that the piperidinium- $\mathrm{N}-\mathrm{H}$ hydrogen atoms involved in forming the intramolecular $\mathrm{N}-\mathrm{H} \cdots \mathrm{O}$ (hydroxyl) hydrogen bonds also form hydrogen bonds to the sulphonyl-O atoms that form a single hydrogen bond, and so these hydrogen atoms are bifurcated. The chloride atom is also bifurcated, accepting hydrogen bonds from the remaining piperidinium-N-H atoms. Connections between the supramolecular chains to consolidate the three-dimensional packing are of the type sulphonate-phenyl- $\mathrm{C}-\mathrm{H} \cdots \pi$ (pyridyl) and $\mathrm{C}-\mathrm{F}^{\cdots} \pi$ (pyridyl, $\mathrm{C}_{6}$ of quinolinyl), Fig. $4 \mathrm{~b}$ and Table 2. Interestingly, in this scheme each of the four rings of the quinolinyl residues accepts a $\mathrm{C}-\mathrm{F}^{\cdots} \pi$ interaction, that one fluoride from each trifluoro group functions as a donor and also that the fluoride atoms bound to the trifluoro group adjacent to the pyridyl-N atom form donor interactions to pyridyl rings. Globally, the structure might be described as layers of anions in the ab-plane sandwiched by layers of mefloquinium cations. The "sandwiches" stack along the $c$-axis, Fig. 4c.

Finally, a further comment on the symmetry of the chosen space group, viz. $P 2{ }_{1} 2{ }_{1} 2_{1}$ versus Pnma, in terms of the packing is apposite. While to a first approximation, the symmetry of the intermolecular interactions match the requirements of the higher symmetry space group, as alluded to above, the variations in the $\mathrm{D} \cdots \mathrm{A}$ distances are as great as 0.05 $\AA$ in some instances, Table 2 . 


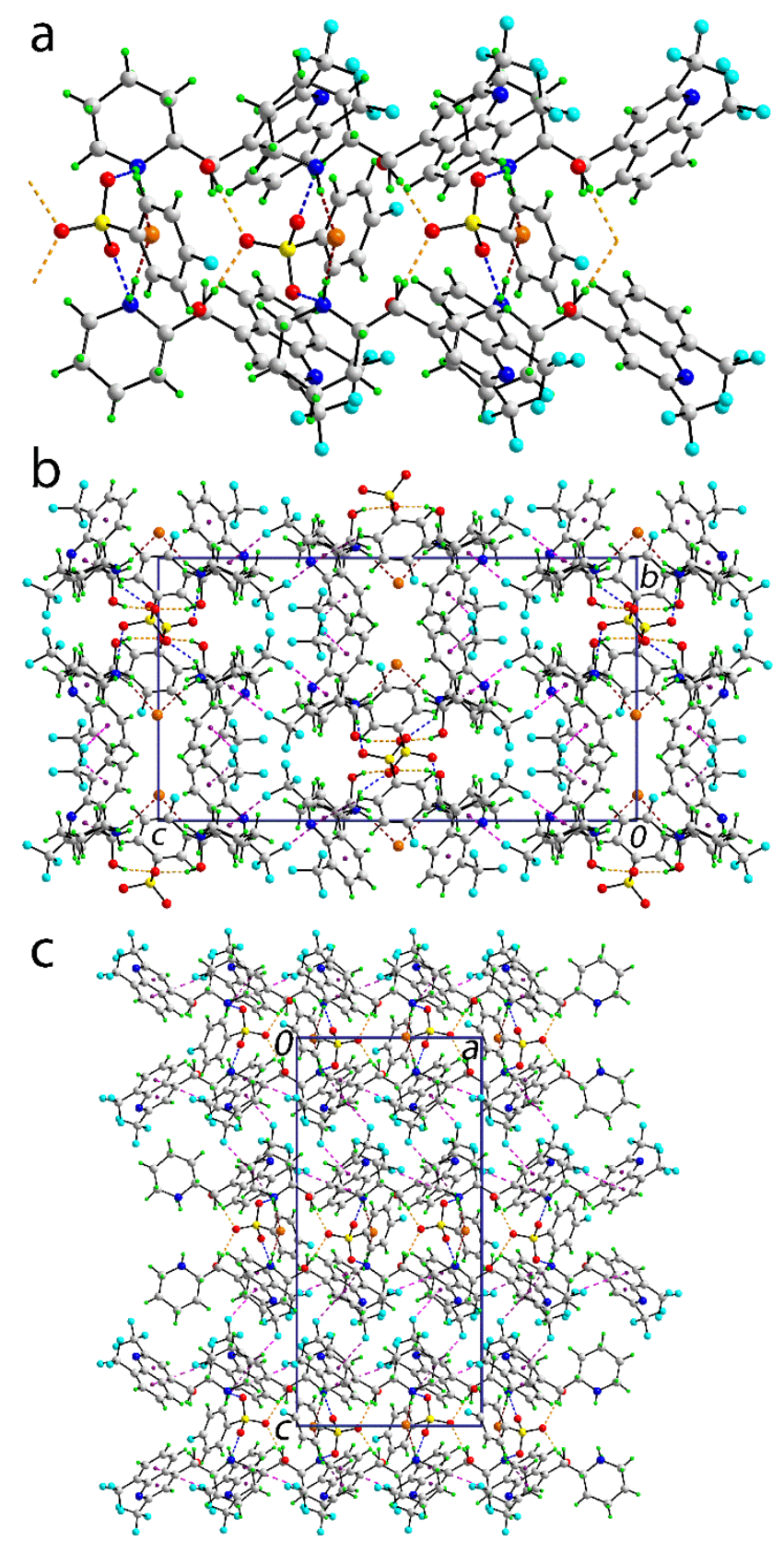

Fig. 4. Molecular packing in 1: (a) A view of the helical supramolecular chain, (b) a view in projection down the $a$ axis of the unit cell contents, (c) a view in projection down the $b$-axis highlighting the stacking of layers. The $\mathrm{O}-\mathrm{H} \cdots \mathrm{O}$, $\mathrm{N}-\mathrm{H} \cdots \mathrm{O}$ and $\mathrm{N}-\mathrm{H} \cdots \mathrm{Cl}$ hydrogen bonds, and $\mathrm{C}-\mathrm{H} \cdots \pi$ and $\mathrm{C}-$ $F^{\cdots} \pi$ interactions are shown as orange, blue, brown, purple and pink dashed lines, respectively.

\section{Structural correlations in mefloquinium cations}

Data for all known isomeric mefloquine [21, 22] and mefloquinium cations [23-30] that have been characterised crystallographically are collected in Table 3 . It is remarkable that the 28 characterised mefloquine/mefloquinium species dis- 
play a high degree of homogeneity in their molecular structures. The major degrees of freedom in the molecules are associated with the link between the quinolinyl residue and the piperidin-2-yl/piperidinium-2-yl-methanol residue, and the geometric relationship between piperidin-2-yl/piperidinium-2-yl-nitrogen and hydroxyl-oxygen atoms. In each molecule, the heteroatoms are orientated to the same side of the molecule. Thus, all $\mathrm{O} \cdots \mathrm{N}$ separations are less than $3.1 \AA$, and the $\mathrm{O}-\mathrm{C}(\mathrm{H})-\mathrm{C}(\mathrm{H})-\mathrm{N}$ torsion angle data indicate a gauche relationship. The piperidin-2-yl/piperidinium-2-ylmethanol residue sits effectively prime with respect to the quinolinyl fused rings system with the $(\mathrm{H}) \mathrm{C}-\mathrm{C}-\mathrm{C}(\mathrm{OH})-$ $\mathrm{C}(\mathrm{H})$ torsion angles being uniformly greater than $90^{\circ}$ and vary up to $107^{\circ}$; in all cases the piperidin-2-yl/piperidinium2-yl rings lies away from the quinolinyl residue. Finally, the $\mathrm{C}-\mathrm{C}(\mathrm{OH})-\mathrm{C}(\mathrm{H})-\mathrm{N}$ torsion angle data indicate an effectively planar and anti arrangement of these atoms with the maximum deviation from planarity being $15.5^{\circ}$. In summary, despite the varied intermolecular interactions operating in their crystal structures, the mefloquine/mefloquinium species exhibit robust molecular conformations.

\section{Hirshfeld surfaces}

In order to gain a greater understanding of the supramolecular association in the crystal structure of $\mathbf{1}$, an analysis of the Hirshfeld surfaces was conducted. Crystal Explorer 3.1 [31] was used to generate Hirshfeld surfaces mapped over $d_{\text {norm }}$, $\mathrm{d}_{\mathrm{e}}$ and the electrostatic potential. The electrostatic potentials were calculated using TONTO $[32,33]$ integrated with Crystal Explorer, wherein the experimental geometry was used as the input for TONTO. Further, the electrostatic potentials were mapped on the Hirshfeld surfaces using the STO-3G basis set at Hartree-Fock level of theory over a range of \pm 0.25 au. The contact distances $d_{i}$ and $d_{e}$ from the Hirshfeld surface to the nearest atom inside and outside, respectively, enables the analysis of the intermolecular interactions through the mapping of $d_{n o r m}$. The combination of $d_{e}$ and $d_{i}$ in the form of a two-dimensional fingerprint plot [34] provides a convenient summary of intermolecular contacts operating in the crystal structure.

The presence of a p-fluorobenzene sulphonate anion on one side and chloride anion on another side of a pair of mefloquinium cations is consistent with the deviation of mefloquinium cations from centrosymmetric behaviour. The displacement of the putative inversion centre due to different anions linked on either side of cations can be easily visualised from the Hirshfeld surfaces mapped over electrostatic potential, Fig. 5. The small blue regions of irregular shape around the piperidinium- and hydroxyl-H-atoms highlight the positive electrostatic potentials, and the comparatively large red regions of negative electrostatic potential around the chloride and sulphonate anions create an asymmetric charge distribution within the molecule. The overall dipole moment also increases due to this charge asymmetry. 
Table 3. Comparison of key geometric parameters $\left(\AA{ }^{\circ}{ }^{\circ}\right)$ for mefloquine $(\mathrm{L})$ and mefloquinium cations $\left(\left[\mathrm{LH}^{+}\right]\right)$.

\begin{tabular}{|c|c|c|c|c|c|c|}
\hline Compound & $\begin{array}{c}\mathrm{N} \cdots \mathrm{O} \\
\text { distance } \\
(\AA)^{a}\end{array}$ & $\begin{array}{c}\mathrm{O}-\mathrm{C}(\mathrm{H})- \\
\mathrm{C}(\mathrm{H})-\mathrm{N} \\
\text { torsion angle } \\
\left({ }^{\circ}\right)\end{array}$ & $\begin{array}{c}(\mathrm{H}) \mathrm{C}-\mathrm{C}- \\
\mathrm{C}(\mathrm{OH})-\mathrm{C}(\mathrm{H}) \\
\text { torsion angle } \\
\left({ }^{\circ}\right)\end{array}$ & $\begin{array}{c}\mathrm{C}-\mathrm{C}(\mathrm{OH})- \\
\mathrm{C}(\mathrm{H})-\mathrm{N} \\
\text { torsion angle } \\
\left({ }^{\circ}\right)\end{array}$ & $\begin{array}{l}\text { Dihedral angle } \\
\qquad\left({ }^{\circ}\right)^{b}\end{array}$ & Ref. \\
\hline \multirow{2}{*}{$( \pm)$-Mefloquine ${ }^{c}$} & $2.782(5)$ & $-61.2(4)$ & $98.9(4)$ & $175.8(3)$ & $69.15(12)$ & {$[21]$} \\
\hline & $2.846(5)$ & $66.5(4)$ & $-107.2(4)$ & $-169.8(3)$ & $76.16(11)$ & \\
\hline \multirow[t]{5}{*}{ (-)-Mefloquine ${ }^{d}$} & $2.754(4)$ & $-58.6(4)$ & $97.8(4)$ & $179.3(3)$ & $68.98(10)$ & {$[22]$} \\
\hline & $2.802(4)$ & $-59.9(4)$ & $101.9(4)$ & $177.8(3)$ & $76.20(10)$ & \\
\hline & $2.827(4)$ & $-64.3(4)$ & $93.6(4)$ & $171.8(3)$ & $64.65(10)$ & \\
\hline & $2.898(5)$ & $-68.8(4)$ & $103.8(4)$ & $168.2(3)$ & $76.23(11)$ & \\
\hline & $2.930(5)$ & $-71.8(4)$ & $96.5(4)$ & $164.5(3)$ & $67.89(11)$ & \\
\hline \multirow[t]{4}{*}{$(-)-\left[\mathrm{LH}^{+}\right] \mathrm{Cl}^{-} 0.25 \mathrm{H}_{2} \mathrm{O}^{e}$} & $2.722(15)$ & $-54.31(12)$ & $103.52(14)$ & $-176.90(10)$ & 76.1(4) & {$[23]$} \\
\hline & $2.840(14)$ & $-60.12(13)$ & $92.66(16)$ & $-179.41(10)$ & $73.3(4)$ & \\
\hline & $2.965(14)$ & $-71.53(12)$ & $97.88(14)$ & $168.48(10)$ & $72.8(4)$ & \\
\hline & $2.848(15)$ & $-69.42(12)$ & $94.78(15)$ & $171.38(10)$ & $67.9(4)$ & \\
\hline \multirow[t]{2}{*}{$(-)-\left[\mathrm{LH}^{+}\right] \mathrm{Cl}^{-} \mathrm{CH}_{3} \mathrm{OH}^{c}$} & $2.7052(18)$ & $54.54(14)$ & $-98.86(17)$ & $176.46(12)$ & $72.71(4)$ & {$[24]$} \\
\hline & $2.7792(16)$ & $-61.37(14)$ & $97.92(17)$ & $176.77(12)$ & $70.41(4)$ & \\
\hline \multirow[t]{3}{*}{$( \pm)-\left[\mathrm{LH}^{+}\right] \mathrm{Cl}^{-} \mathrm{H}_{2} \mathrm{O}^{f}$} & $2.912(3)$ & $-66.80(23)$ & $110.86(24)$ & $171.66(18)$ & $88.9(6)$ & {$[24]$} \\
\hline & $2.720(3)$ & $-56.1(2)$ & $104.5(3)$ & 177.70(19) & $77.4(6)$ & \\
\hline & $2.963(3)$ & $73.6(2)$ & $-93.7(3)$ & $-164.47(18)$ & $69.2(6)$ & \\
\hline$( \pm)-\left[\mathrm{LH}^{+}\right] \mathrm{Cl}^{-} \mathrm{CH}_{3} \mathrm{OH}$ & $2.792(5)$ & $-62.7(5)$ & $95.9(5)$ & $174.6(4)$ & $69.31(14)$ & {$[25]$} \\
\hline$( \pm)-\left[\mathrm{LH}^{+}\right] \mathrm{BPh}_{4}^{-} \mathrm{CH}_{3} \mathrm{CH}_{2} \mathrm{OH}$ & $2.701(3)$ & $-53.0(2)$ & $98.9(3)$ & $-174.91(19)$ & $70.40(7)$ & [26] \\
\hline$( \pm)-\left[\mathrm{LH}^{+}\right]\left[2-\mathrm{NO}_{2}-\mathrm{C}_{6} \mathrm{H}_{4} \mathrm{CO}_{2}\right]^{-}$ & $2.914(2)$ & $-72.8(2)$ & $97.3(3)$ & $165.23(18)$ & $67.8(6)$ & [27] \\
\hline$( \pm)-\left[\mathrm{LH}^{+}\right]\left[3-\mathrm{NO}_{2}-\mathrm{C}_{6} \mathrm{H}_{4} \mathrm{CO}_{2}\right]^{-}$ & $2.7590(19)$ & $-59.34(18)$ & $101.00(21)$ & $178.39(15)$ & $81.45(4)$ & {$[27]$} \\
\hline$( \pm)-\left[\mathrm{LH}^{+}\right]\left[4-\mathrm{NO}_{2}-\mathrm{C}_{6} \mathrm{H}_{4} \mathrm{CO}_{2}\right]^{-}$ & $2.756(4)$ & $-54.1(4)$ & $100.5(4)$ & $-175.1(3)$ & $80.99(9)$ & {$[27]$} \\
\hline $\begin{array}{l}( \pm)-\left[\mathrm{LH}^{+}\right]\left[3-\mathrm{NH}_{2}-5-\mathrm{NO}_{2}-\mathrm{C}_{6} \mathrm{H}_{4} \mathrm{CO}_{2}\right]^{-} \\
1.5 \mathrm{H}_{2} \mathrm{O}\end{array}$ & $2.867(3)$ & $66.0(3)$ & $-102.9(3)$ & $-171.57(20)$ & $75.68(7)$ & {$[28]$} \\
\hline$( \pm)-\left[\mathrm{LH}^{+}\right]_{2}\left[\mathrm{CuCl}_{4}\right]^{2-} 4 \mathrm{H}_{2} \mathrm{O}$ & $2.886(5)$ & $-67.4(4)$ & $103.2(4)$ & $169.6(3)$ & $78.35(11)$ & {$[29]$} \\
\hline$( \pm)-\left[\mathrm{LH}^{+}\right]_{2}\left[\mathrm{CdBr}_{4}\right]^{2-} \cdot 2 \mathrm{CH}_{3} \mathrm{OH}$ & $2.727(5)$ & $58.6(5)$ & $-99.6(6)$ & $179.9(4)$ & $72.94(13)$ & [29] \\
\hline \multirow[t]{3}{*}{$\begin{array}{l} \pm( \pm)-\left[\mathrm{LH}^{+}\right]_{3}\left[\mathrm{CoCl}_{4}\right]^{2-} \mathrm{Cl}^{-} \\
\mathrm{H}_{2} \mathrm{OCCH}_{3} \mathrm{CH}_{2} \mathrm{OH}^{f}\end{array}$} & $2.710(4)$ & $59.3(3)$ & $-104.3(3)$ & $-179.3(3)$ & $73.46(7)$ & {$[21]$} \\
\hline & $3.062(4)$ & $75.2(3)$ & $-98.9(4)$ & $-165.7(3)$ & $70.06(10)$ & \\
\hline & $2.870(4)$ & 69.5(3) & $-102.2(3)$ & $-169.0(2)$ & $65.88(9)$ & \\
\hline$( \pm)-\left[\mathrm{LH}^{+}\right]_{2}\left[\mathrm{Ph}_{2} \mathrm{SnCl}_{4}\right]^{2-}$ & $2.789(8)$ & $-65.2(7)$ & $101.0(8)$ & $173.2(6)$ & $67.6(2)$ & {$[30]$} \\
\hline
\end{tabular}

$a$ Intramolecular piperidine/piperidinium- $\mathrm{N} \cdots \mathrm{O}$ (hydroxyl) distance. $b$ Dihedral angle between the best planes through the piperidin-1-ium and quinoline rings. $c$ Two independent mefloquine molecules or $\left[\mathrm{LH}^{+}\right]$cations in the asymmetric unit. $d$ Five independent mefloquine molecules in the asymmetric unit. $e$ Four independent $\left[\mathrm{LH}^{+}\right]$cations in the asymmetric unit. $f$ Three independent $\left[\mathrm{LH}^{+}\right]$cations in the asymmetric unit.
Author
Title
File Name
Mukesh M. Jotani, James L. Crystal structure and Hirshfeld analysis of the krytoracemate: bis(mefloquinium) mef.docx Date Page

Wardell and Edward R. T. Tiek- chloride p-fluorobenzenesulphonate 


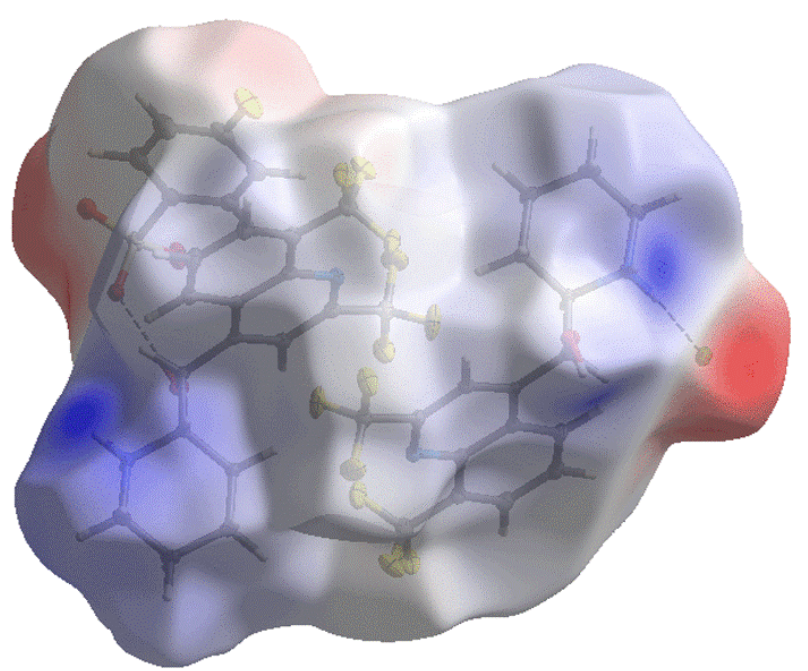

Fig. 5. Hirshfeld surfaces for the asymmetric unit of $\mathbf{1}$ mapped over the electrostatic potential highlighting the regions of high electron density (red) and electropositive regions (blue).

The nature of intermolecular interactions involved in the overall packing also provides a useful explanation of the construction of the non-centrosymmetric space group. The Hirshfeld surfaces together with two-dimensional fingerprint plots enable the visualisation of the significant intermolecular interactions. The presence of potential intermolecular O$\mathrm{H} \cdots \mathrm{O}, \mathrm{N}-\mathrm{H} \cdots \mathrm{Cl}$ and $\mathrm{N}-\mathrm{H} \cdots \mathrm{O}$ interactions in the packing can be easily confirmed through the appearance of bright-red spots near corresponding pairs of donor and acceptor atoms on the Hirshfeld surface mapped with $\mathrm{d}_{\text {norm }}$ and examples are designated as $\mathbf{1}(\mathrm{O}-\mathrm{H} \cdots \mathrm{O}), \mathbf{2}, 3\left(\mathrm{~N}-\mathrm{H}^{\cdots} \mathrm{O}\right)$ and $\mathbf{4}(\mathrm{N}-\mathrm{H} \cdots \mathrm{Cl})$ in the square boxes in Fig. 6 . The role of donors and acceptors in these interactions are also evident from respective blue and red regions on the Hirshfeld surfaces mapped with electrostatic potential (Fig. 5).

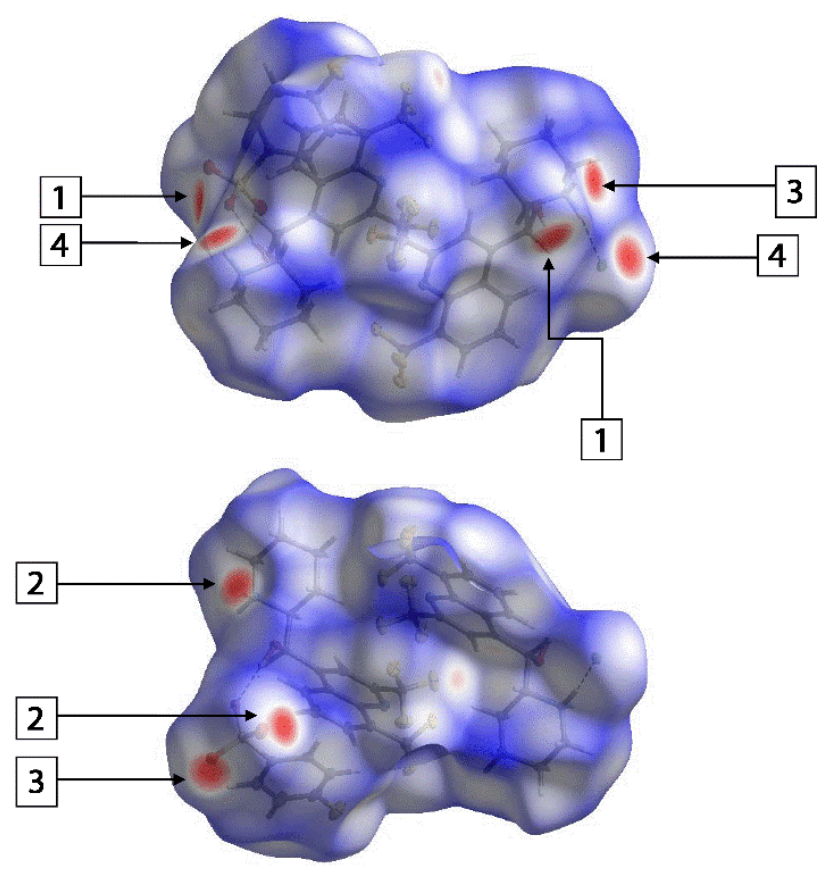


Fig. 6. Two views of the Hirshfeld surfaces for 1 mapped over

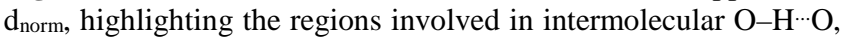
$\mathrm{N}-\mathrm{H} \cdots \mathrm{Cl}$ and $\mathrm{N}-\mathrm{H} \cdots \mathrm{O}$ interactions.

The overall two-dimensional fingerprint plot, Fig. 7a, has been delineated into $\mathrm{H} \cdots \mathrm{H}, \mathrm{F} \cdots \mathrm{H} / \mathrm{H} \cdots \mathrm{F}, \mathrm{O} \cdots \mathrm{H} / \mathrm{H} \cdots \mathrm{O}, \mathrm{C} \cdots \mathrm{H} / \mathrm{H} \cdots \mathrm{C}$, $\mathrm{Cl} \cdots \mathrm{H} / \mathrm{H} \cdots \mathrm{Cl}$ and $\mathrm{F} \cdots \mathrm{F}$ contacts as illustrated in Figs $7 \mathrm{~b}-\mathrm{g}$; the relative contributions of all identified interactions are collected in Table 4.

Table 4. Relative contributions of various intermolecular contacts to the Hirshfeld surface area of $\mathbf{1}$.

\begin{tabular}{|l|c|}
\hline Contact & \% Contribution \\
\hline $\mathrm{H} \cdots \mathrm{H}$ & 29.3 \\
\hline $\mathrm{F} \cdots \mathrm{H} / \mathrm{H} \cdots \mathrm{F}$ & 28.7 \\
\hline $\mathrm{O} \cdots \mathrm{H} / \mathrm{H}^{\cdots} \mathrm{O}$ & 14.4 \\
\hline $\mathrm{C} \cdots \mathrm{H} / \mathrm{H} \cdots \mathrm{C}$ & 7.6 \\
\hline $\mathrm{Cl} \cdots \mathrm{H} / \mathrm{H} \cdots \mathrm{Cl}$ & 7.3 \\
\hline $\mathrm{F} \cdots \mathrm{F}$ & 7.2 \\
\hline $\mathrm{C} \cdots \mathrm{F}$ & 2.5 \\
\hline $\mathrm{C} \cdots \mathrm{C}$ & 0.8 \\
\hline $\mathrm{N} \cdots \mathrm{H} / \mathrm{H} \cdots \mathrm{N}$ & 0.7 \\
\hline $\mathrm{C} \cdots \mathrm{O} / \mathrm{O} \cdots \mathrm{C}$ & 0.6 \\
\hline $\mathrm{F} \cdots \mathrm{O} / \mathrm{O} \cdots \mathrm{F}$ & 0.4 \\
\hline $\mathrm{O} \cdots \mathrm{O}$ & 0.3 \\
\hline $\mathrm{F} \cdots \mathrm{Cl} / \mathrm{Cl} \cdots \mathrm{F}$ & 0.3 \\
\hline
\end{tabular}

The contribution from dispersive forces to the overall Hirshfeld surface is reflected in the middle of the scattered points by $\mathrm{H} \cdots \mathrm{H}$ contacts, Fig. $7 \mathrm{~b}$, as well as from $\mathrm{F} \cdots \mathrm{F}$ contacts having a single spike in the plot, Fig. $7 \mathrm{~g}$, superimposed at $d_{\mathrm{e}}$ $+\mathrm{d}_{\mathrm{i}} \sim 2.3 \AA$ with 29.3 and $7.2 \%$ contributions, respectively. It is interesting to note that $\mathrm{F} \cdots \mathrm{H} / \mathrm{H} \cdots \mathrm{F}$ contacts also have significant contribution, i.e. $28.7 \%$, to the surface despite the absence of intermolecular $\mathrm{C}-\mathrm{H} \cdots \mathrm{F}$ interactions, Fig. 7c. The pair of spikes at comparatively short $\mathrm{d}_{\mathrm{e}}+\mathrm{d}_{\mathrm{i}} \sim 1.8 \AA$ and 14.4 $\%$ contribution from $\mathrm{O} \cdots \mathrm{H} / \mathrm{H} \cdots \mathrm{O}$ contacts to the surfaces, Fig. $7 \mathrm{~d}$, indicate that $\mathrm{O}-\mathrm{H} \cdots \mathrm{O}$ and $\mathrm{N}-\mathrm{H} \cdots \mathrm{O}$ are the most significant directional intermolecular interactions in the crystal structure. The fingerprint plot showing $7.6 \%$ contribution from $\mathrm{C} \cdots \mathrm{H} / \mathrm{H} \cdots \mathrm{C}$ contacts, Fig. 7e and the bright orange spot encircled around (C1-C4, C9, N1) ring of quinoline moiety, Fig. 8 , indicate the contribution from $\mathrm{C}-\mathrm{H}^{\cdots} \pi$ interactions. The intermolecular interactions of the type $\mathrm{N}-\mathrm{H} \cdots \mathrm{Cl}\left(\mathrm{d}_{\mathrm{e}}+\mathrm{d}_{\mathrm{i}} \sim\right.$ $2.05 \AA$ ) with a $7.3 \%$ contribution is indicated by a pair of long and sharp spikes in Fig. 3f. 

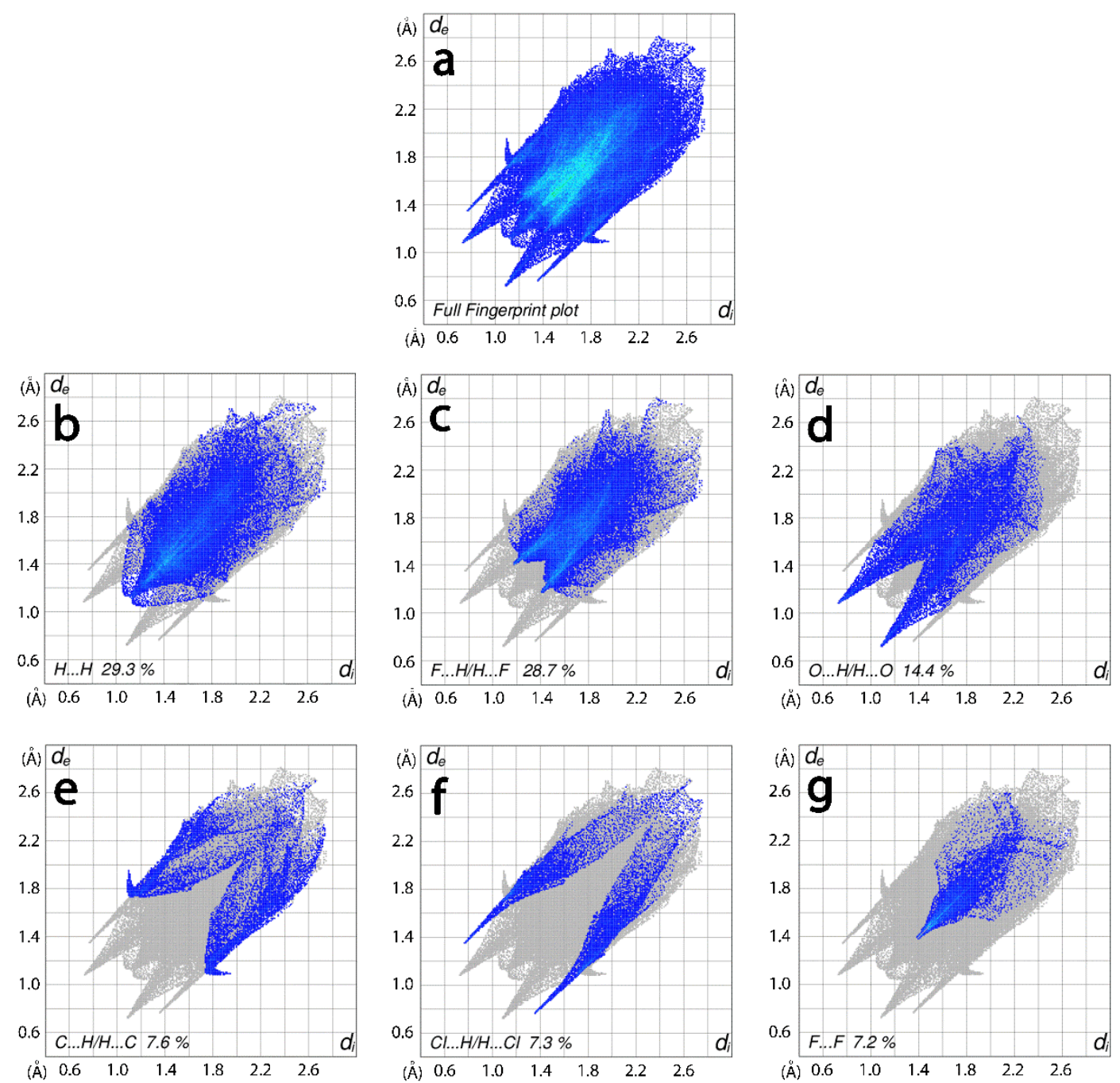

Fig. 7. Fingerprint plots calculated for 1: (a) overall plot, and plots delineated into (b) $H \cdots H$, (c) $F \cdots H / H \cdots F$, (d) $\mathrm{O} \cdots H / H \cdots O$, (e) $\mathrm{C} \cdots \mathrm{H} / \mathrm{H} \cdots \mathrm{C}$, (f) $\mathrm{Cl} \cdots \mathrm{H} / \mathrm{H} \cdots \mathrm{Cl}$, and (g) $\mathrm{F} \cdots \mathrm{F}$ contacts. $\begin{array}{lllll}\text { Author } & \text { Title } & \text { File Name } & \text { Date } & \text { Page } \\ \text { Mukesh M. Jotani, James L. } & \text { Crystal structure and Hirshfeld analysis of the krytoracemate: bis(mefloquinium) } & \text { mef.docx } & 30.10 .2017 & 14(16) \\ \text { Wardell and Edward R. T. Tiek- } & \text { chloride p-fluorobenzenesulphonate } & & \end{array}$ 


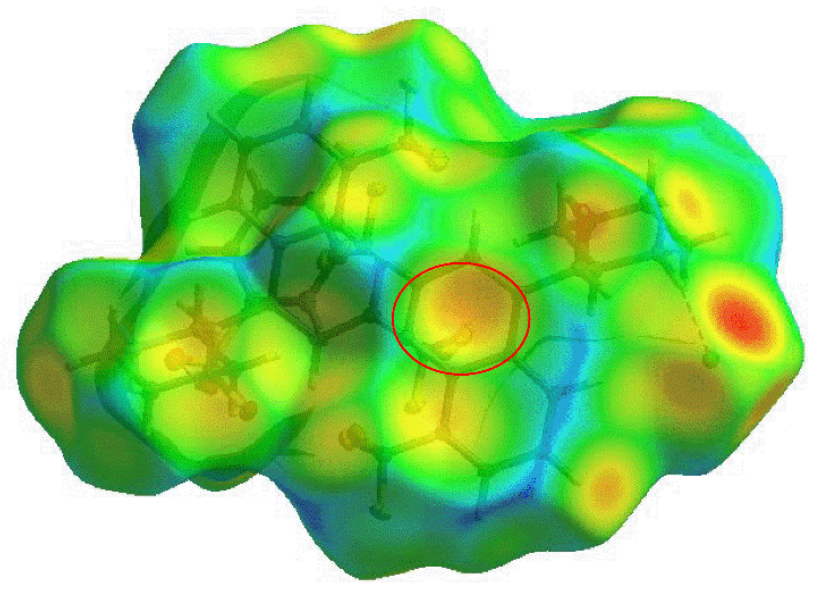

Fig. 8. Hirshfeld surface mapped over $d_{e}$ for $\mathbf{1}$ highlighting the quinolinyl ring involved in the $\mathrm{C} \cdots \mathrm{H} / \mathrm{H} \cdots \mathrm{C}$ contacts.

\section{Conclusions}

The crystallographically independent (enantiomeric) cations in the structure of kryptoracemate 1, exhibit a pseudo centrosymmetric relationship but, display very similar molecular conformations, as indeed observed for two-thirds of identified kryptoracemates [11]. Indeed, all crystallographically determined mefloquine/mefloquinium species exhibit very similar molecular conformations. It is likely that in the case of $\mathbf{1}$, that the kryptoracemic behaviour arises as a result of the preferential crystallisation of a mixed salt, rather than the anticipated 1:1 mefloquinium:p-fluorobenzenesulphonate salt. The different anions induce asymmetric supramolecular associations as revealed in a detailed analysis of the molecular packing.

Acknowledgments. The use of the EPSRC X-ray crystallographic service at the University of Southampton, England, and the valuable assistance of the staff there is gratefully acknowledged. JLW also acknowledges support from CAPES (Brazil).

\section{References}

[1] J. D. Maguire, Krisin, H. Marwoto, T. L. Richie, D. J. Fryauff, J. K. Baird, Clin. Infect. Dis. 2006, 42, 1067.

[2] C. M. Kunin, W. Y. Ellis, Antimicrob. Agents. Chemother. 2000, 44,848

[3] J. Mao, Y. Wang, B. Wan, A. P. Kozikowski, S. G. Franzblau, ChemMedChem 2007, 2, 1624.

[4] S. Jayaprakash, Y. Iso, B. Wan, S. G. Franzblau, A. P. Kozikowski, ChemMedChem 2006, 1, 593.

[5] R. S. B. Goncalves, C. R. Kaiser, M. C. S. Lourenco, F. A. F. M. Bezerra, M. V. N. de Souza, J. L. Wardell, S. M. S. V. Wardell, M. das G. M. de O. Henriques, T. Costa, Bioorg. Med. Chem. 2012, 20, 243.

[6] L. E. Bermudez, P. Kolonoski, L. E. Seitz, M. Petrofsky, R. Reynolds, M. Wu, L. S. Young, Antimicrob. Agents Chemother. 2004, 48, 3556.

[7] M.V. N. de Souza, R. S. B. Goncalves, F. A. R. Rodrigues, B. C. Cavalcanti, I. da S. Bomfim, C. do Ó Pessoa, J. L. Wardell and S. M. S. V. Wardell, Chem. Biol. Drug Des. 2014, 83, 126. 
[8] I. Bernal, ACA Annual Meeting, Montreal, Quebec, Canada, 1995. Abstract 4.a.1.e.

[9] E. Pidcock, W. D. S. Motherwell, J. C. Cole, Acta Crystallogr. B 2003, 59, 634.

[10] E. Pidcock, Chem. Commun. 2005, 3457.

[11] L. Fabian, C. P. Brock, Acta Crystallogr. B 2010, 66, 94.

[12] I. Bernal, S. Watkins, Acta Crystallogr. C 2015, 71, 216.

[13] CrystalClear-SM Expert. User Manual. Rigaku/MSC Inc., Rigaku Corporation, The Woodlands, TX, 2011.

[14] G. M. Sheldrick, Acta Crystallogr. A 2008, 64, 112.

[15] G. M. Sheldrick, Acta Crystallogr. C 2015, 71, 3.

[16] L. J. Farrugia, J. Appl. Crystallogr. 2012, 45, 849.

[17] A. L. Spek, Acta Crystallogr. D 2009, 65, 148.

[18] J. Gans, D. Shalloway, J. Mol. Graph. Model. 2001, 19, 557.

[19] DIAMOND, Visual Crystal Structure Information System, Version 3.1, CRYSTAL IMPACT, Postfach 1251, D-53002, 2006.

[20] C. F. Macrae, I. J. Bruno, J. A. Chisholm, P. R. Edgington, P. McCabe, E. Pidcock, L. Rodriguez-Monge, R. Taylor, J. van de Streek, P. A. Wood, J. Appl. Crystallogr. 2008, 41, 466.

[21]. A. Skórska, J. Śliwiński, B. J. Oleksyn, Bioorg. Med. Chem. Lett. 2006, 16, 850.

[22] A. Dassonville-Klimpt, C. Cezard, C. Mullie, P. Agnamey, A. Jonet, S. Da Nascimento, M. Marchivie, J. Guillon, P. Sonnet, ChemPlusChem 2013, 78, 642.

[23] J. M. Karle, I. L. Karle, Antimicrob. Agents Chemother. 2002, 46, 1529.

[24] A. Pitaluga, L. D. Prado, R. Seisceiras, J. L. Wardell, S. M. S. V. Wardell, Int. J. Pharm. 2010, 398, 50.

[25] J. M. Karle, I. L. Karle, Acta Crystallogr. C 1991, 47, 2391.

[26] J. L. Wardell, M. V. N. de Souza, S. M. S. V. Wardell, M. C. S. Lourenco, J. Mol. Struct. 2011, 990, 67.

[27] S. M. S. V. Wardell, J. L. Wardell, J. M. S. Skakle, E. R. T. Tiekink, Z. Kristallogr. 2011, 226, 68.

[28] M. V. N. de Souza, J. L. Wardell, S. M. S. V. Wardell, S. W. Ng, E. R. T. Tiekink, Acta Crystallogr. E 2011, 67, o3019.

[29] J. A. Obaleye, M. R. Caira, A. C. Tella, Struct. Chem. 2009, $20,859$.

[30] J. L. Wardell, S. M. S. V. Wardell, E. R. T. Tiekink, G. M. de Lima, Acta Crystallogr. E 2010, 66, m336.

[31] S. K. Wolff, D. J. Grimwood, J. J. McKinnon, M. J. Turner, D. Jayatilaka, M. A. Spackman, Crystal Explorer (Version 3.1), University of Western Australia, 2012.

[32] M. A. Spackman, J. J. McKinnon, D. Jayatilaka, CrystEngComm 2008, 10, 377.

[33] D. Jayatilaka, D. J. Grimwood, A. Lee, A. Lemay, A. J. Russel, C. Taylor, C., S. K. Wolff, C. Chenai, A. Whitton, TONTO - A System for Computational Chemistry, 2005. Available at: http://hirshfeldsurface.net/

[34] A. L. Rohl, M. Moret, W. Kaminsky, K. Claborn, J. J. Mackinon, B. Kahr, Cryst. Growth Des. 2008, 8, 4517. 